\title{
Phenytoin-induced toxicity in the postnatal cerebellar development in rat: effect of calotropis procera on selective biochemical and haematological variables
}

\author{
Innocent O. IMOSEMI ${ }^{1,2, *}$, Abraham A. OSINUBI ${ }^{2}$, Linus C. SAALU ${ }^{2}$ and \\ Joseph A. OLAGUNJU ${ }^{2}$ \\ ${ }^{1}$ Department of Anatomy, College of Medicine, University of Ibadan, Ibadan. Nigeria. \\ ${ }^{2}$ Department of Anatomy, College of Medicine, Lagos State University, Ojoo, Lagos. Nigeria. \\ "Corresponding author; E-mail: innosemi@yahoo.co.uk; Tel: +234-7068025958.
}

\begin{abstract}
Phenytoin, an antiepileptic drug is used in managing seizures. Phenytoin-associated oxidative stress causes cellular damage by the generation of free radicals. Vitamin C, a standard antioxidant and Calotropis procera are believed to scavenge oxygen free radicals. The effect of $C$. procera extract on haematological and biochemical variables in an in-vivo model was studied. Pregnant rats were administered phenytoin $(50 \mathrm{mg} / \mathrm{kg}$ body weight). Extracts of $C$. procera (300 mg/kg body weight) and vitamin C ( $200 \mathrm{mg} / \mathrm{kg}$ body weight) were administered one hour prior to phenytoin treatment separately, while control animals received tap water only. The animals had access to food and water ad libitum. Blood was collected from animals on day 50 postpartum for packed cell volume (PCV), haemoglobin $(\mathrm{Hb})$ content and evaluation of levels of alanine aminotransferase (ALT) and aspartate aminotransferase (AST) evaluation. Lipid peroxidase (LPO) and reduced glutathione (GSH) levels in the cerebellum were assessed as markers of oxidative stress on day 50 postpartum. Phenytoininduced toxicity was associated with increased cerebellar LPO and decreased GSH levels. Increase in ALT and AST levels in the serum was observed. However, PCV and Hb levels were not affected. LPO, GSH, ALT and AST levels registered a tendency to shift towards normalcy on administration of $C$. procera and vitamin $\mathrm{C}$ to phenytoin. In conclusion, supplementation with $C$. procera leaf extract reduced the rate at which phenytoin induced toxicity in developing rat cerebellum postnatally.
\end{abstract}

(C) 2010 International Formulae Group. All rights reserved.

Keywords: Phenytoin, Calotropis procera, cerebellar development, oxidative stress, antioxidants

\section{INTRODUCTION}

Phenytoin is prescribed for infants with seizure disorders (Appleton et al., 2002; Buck, 1996; McNamara, 2001). The behavioral teratogenicity induced on prenatal exposure to phenytoin is well established (Vorhees, 1994; Tachibana, 1996). Phenytoin is thought to cause chronic intrauterine hypoxia/ischaemia and embryo-foetal toxicity via reacting oxygen intermediates. Reacting oxygen species (ROS) can oxidize molecular targets such as Deoxynucleic acid (DNA), protein, lipid in a process called oxidative stress resulting in cellular dysfunction and in utero death or teratogenicity (Wells et al., 1996; Zablocka and Janusz, 2008). 
Oxidative stress occurs due to an imbalance in prooxidant and antioxidant levels. Scientific evidence suggests that under oxidative stress conditions, oxygen radicals such as superoxide anion $\left(\mathrm{O}_{2}^{-}\right)$, hydroxyl radical $\left(\mathrm{OH}^{-}\right)$and peroxyl radicals $\left(\mathrm{ROO}^{-}\right)$are produced in biological systems. These oxygen radicals play important roles in degenerative processes such as ageing, cardiovascular diseases, cancer, Alzheimer's disease, stroke, Parkinson's disease and other neurodegenerative diseases, (Ames, 1983; Gey, 1990; Smith et al., 1996; Temple, 2000; Chatterjee et al., 2007). Phenytoin administration has been reported to be associated with cerebellar atrophy and persistent cerebellar ataxia with clinical manifestation presenting as confusion, slurred speech and nastagmus following acute and long-term intoxication (Imamura et al., 1992; Ney et al., 1994) and temporal cerebellar atrophy following phenytoin therapy (Guerrero et al., 1997). To prevent free radical-induced cellular damage generated by phenytoin and other neurotoxicants, the human body has developed a defense mechanism-the antioxidants system. This system includes, endogenous antioxidant enzymes such as superoxide dismutase (SOD), catalase (CAT), glutathione peroxidase (GSHPx) and glutathione reductase (GSSGR), low molecular antioxidants such as glutathione (GSH) and plasma proteins, and exogenous antioxidants such as vitamins $\mathrm{C}, \mathrm{E}$ and $\beta$-carotene (Zablocka and Janusz, 2008). Glutathione plays a key role in maintaining the physiological balance between pro-oxidant and antioxidants. Plasma proteins, vitamins $\mathrm{C}$ and $\mathrm{E}$ can inhibit ROS generation and lipid peroxidation by chelating free transition metals such as copper and iron (Zablocka and Janusz, 2008).

The antioxidant activity of some plants such as Kolaviron, Calotropis procera and Vernonia amygdalina which are thought to scavenge the oxygen free radicals have been documented (Rao and Dubey, 1990). C. procera also known as the giant milk weed is one of the flowering plants commonly found in tropical regions of the world. The plant is found in almost all parts of Nigeria but more abundantly in the Northern part of the country (Sofowora, 1984). C. procera is a perennial grayish green, woody shrub with broad ovate fleshy leaves that grow wild in the tropics and warm temperate regions (Huber, 1985; Hussein et al., 1994). It derived its common name, giant milk weed, from the thick white sap which oozes from a cut stem or from the stem when a leaf is plucked off. Hence, the family to which the plant belongs is referred to as milkweed family (Ghazanfar, 1989). Edman (1983), Mossa et al. (1991), Al-Robai et al. (1993a) and Hussein et al. (1994) reported the presence of alkaloids, flavonoids, cardiac glycosides, tannins, triterpenes steroids and uscharin in the entire plant of $C$. procera. Ethnomedical practitioners have paid considerable attention to the use of $C$. procera (NAPRALET, 1984). Anis and Iqbal (1986) showed that $C$. procera has antimalarial and anticholeral effects when used as one of the multi component decoction in traditional medicine. Srivastava et al. (1962) reported fibrinolytic and anticoagulant activities of $C$. procera, while Tariq et al. (1984) demonstrated the neuromuscular blocking activity of the plant in mouse. Padhy et al. (2007) evaluated the antioxidant and antiinflammatory properties of the latex of $C$. procera for its hepatoprotective effect against carbon tetrachloride-induced hepatotoxicity in rats. A number of clinical studies suggest that the antioxidants in fruits and vegetables are key factors in reducing the incidence of chronic diseases including heart disease and some cancers (Salah et al., 1995; Gerber et al., 2002; Kris-Etherton et al., 2002; Serafini et al., 2002). This research will test the hypothesis that leaf extracts of C. procera, can protect or reduce phenytoin-induced oxidative stress in developing rat cerebellum postnatally. 


\section{MATERIALS AND METHODS}

Animals

Twenty sexually matured female rats weighing about $160 \mathrm{~g}$ of Wistar strain were obtained from the central animal house of the Faculty of Basic Medical Sciences, University of Ibadan, Ibadan, Oyo State. The animals were randomly divided into five groups of four animals per group. They were mated and pregnancy confirmed by the presence of vaginal plug. The animals were fed with standard diet of rat pellets and water provided ad libitum. All procedures on animal handling conformed to the acceptable guidelines on the ethical use of animals in research.

\section{Drug preparation and administration}

Phenytoin dissolved in tap water was administered orally in pre and postnatal life at the dose of $50 \mathrm{mg} / \mathrm{kg}$. Sodium salt of Phenytoin (capsule) manufactured by Man care Pharmaceuticals PVT Ltd India purchased from the pharmacy, University College Hospital (UCH), Ibadan was used for the experiment.

Two hundred (200) mg/kg body weight vitamin $\mathrm{C}$ was administered one hour orally prior to phenytoin administration, to the experimental animals in pre and post natal life.

\section{Extraction of $C$.procera leaves}

The leaves of $C$. procera were harvested within the main campus of the University of Ibadan and authenticated by Dr. O.A. Ugbogu of the Forestry Research Institute of Nigeria (FRIN), Ibadan with a Forestry Harberium Identification number (FHI) 108221. They were air-dried at room temperature for two and a half months, blended and made into powdered form of about $1.2 \mathrm{~kg}$. Cold methanolic extraction for about 72 hours was done. The methanolic solution was concentrated with rotatory evaporator at a temperature below $50{ }^{\circ} \mathrm{C}$ for 7 hours. The concentrated extract $(187.0 \mathrm{~g})$ was stored in the refrigerator until use. The concentrated extract was reconstituted with water before administration.

Phytochemical studies of the leaves of C. procera was done in the Department of Pharmacognosy, Faculty of Pharmacy, University of Ibadan, Ibadan. The following compounds were screened for: alkaloids, flavonoids, cardenolides, saponins and tannins.

Three hundred (300) $\mathrm{mg} / \mathrm{kg}$ body weight methanolic extract of $C$. procera was administered one hour orally prior to phenytoin administration, to the experimental animals in pre and post natal life. The dose of C. procera extracts used in the research was based on a safety evaluation studies carried out by Mossa et al. (1991) that the use of the extract in a single high doses (up to $3 \mathrm{~g} / \mathrm{kg}$ body weight) does not produce any visible toxic symptoms or mortality.

\section{Grouping of animals}

Group I: Control group received water

Group II: Received $50 \mathrm{mg} / \mathrm{kg}$ phenytoin

Group III: Received 200 mg/kg Vitamin C + phenytoin

Group IV: Received $300 \mathrm{mg} / \mathrm{kg}$ Calotropis procera

Group V: Received Calotropis procera + phenytoin

At the end of the experiment, blood samples were collected under anaesthesia from the animals on day 50 postpartum (ten per group), five animals for haematological studies, pack cell volume (PCV) and haemoglobin $(\mathrm{Hb})$ content, and five animals (serum) hepatocellular enzyme assays, alanine transaminase (ALT) and aspartate transaminase (AST). The animals (five per group) were then killed, the cerebellum dissected out and preserved in phosphate buffer at $4{ }^{\circ} \mathrm{C}$ and a $\mathrm{pH}$ of 7.4 for lipid peroxidation (LPO) and reduced glutathione (GSH) levels. 
Estimation of packed cell volume (PCV) and haemoglobin $(\mathrm{Hb})$

Having collected the blood samples from day 50 postpartum animals into the EDTA bottles, heparinized capillary tubes were used to collecte blood from the EDTA bottles. One end of the capillary tube was sealed with plastacin. The capillary tubes were then centrifuged using a microhaematocrit centrifuge at $5000 \mathrm{~g}$, after which the PCV were determined using a haematocrit reader. PCV was expressed in percentage. Haemoglobin concentration was estimated from the PCV by dividing the value of the $\mathrm{PCV}$ by a factor of 3 . It was expressed in $\mathrm{mg} / \mathrm{dl}$.

Determination of alanine aminotransferase (ALT) and aspartate aminotransferase (AST) activities

The quantitative in vitro determination of alanine aminotransferase (ALT) and aspartate aminotransferase (AST) in the serum were carried out with the aid of Randox kits. (Randox Laboratories Ltd., United Kingdom). ALT and AST activities were determined following the principles described by Reitman and Frankel (1957).

\section{Assessment of lipid peroxidation (LPO)}

Lipid-peroxidation was determined by measuring the thiobarbituric acid reactive (TBAR) products present in the cerebellar tissue using the procedure of Vashney and Kale (1970) and expressed as micromolar of malondialdehyde (MDA)/g tissue.

\section{Determination of reduced glutathione (GSH) levels}

The levels of reduced glutathione (GSH) in the cerebellar tissues were determined by the method described by Beutler et al. (1963).

\section{Statistical analysis}

The data obtained was further analyzed with unpaired student $t$-test using computer software, Microsoft Excel. The Mean, Standard Deviation, SD, and the level of significance at $95 \%$ Confidence Interval calculated.

\section{RESULTS}

Phytochemistry

Phytochemical studies carried out on the leaves of $C$. procera showed that it contained mainly flavonoids, alkaloids and some cardenolides.

Haematological changes in the blood samples of day 50 postpartum animals

No significant difference was observed in the packed cell volume and haemoglobin content in the blood samples on day 50 postpartum in the control and treated animals, $\mathrm{P}>0.05$ (Table 1).

Biochemical changes in the cerebellum of day 50 animals postpartum

An increased rate of lipid peroxidation (LPO) $(4.00 \pm 2.19 \mu \mathrm{mol} / \mathrm{g}$ cerebellar tissue vs $1.8 \pm 1.49 \mu \mathrm{mol} / \mathrm{g}$ cerebellar tissue) and a decreased glutathione (GSH) levels $(1.6 \pm 0.5$ $\mu \mathrm{g} /$ cerebellar tissue vs $2.0 \pm 0.7 \mu \mathrm{g} /$ cerebellar tissue) at $\mathrm{P}>0.05$ was observed in phenytointreated animals when compared with the control group. Administration of vitamin $\mathrm{C}$ and extracts of $C$. procera to phenytointreated animals decreased the rate of lipid peroxidation and increased the glutathione levels in the cerebellum when compared with phenytoin-treated animals (Table 2).

Changes in the hepatocellular enzymes, ALT and AST on day 50 postpartum

A non significant elevation in ALT, $\mathrm{P}>0.05$ and a significant elevation in AST, $\mathrm{P}<0.05(203.4 \pm 34.5 \mathrm{IU} / \mathrm{l}$ vs $162.0 \pm 15.5 \mathrm{IU} / \mathrm{l})$ was seen in the phenytoin-treated animals compared with the control group. Administration of vitamins $\mathrm{C}$ and extracts of C. procera decreased the total activities of ALT and AST at P>0.05 when compared with phenytoin-treated animals. Vitamin C administered to phenytoin-treated animals significantly decreased the level of ALT when compared with phenytoin-treated group, $\mathrm{P}<0.05 \quad(60.0 \pm 3.8 \quad \mathrm{IU} / \mathrm{l}$ vs $73.6 \pm 10.4 \mathrm{IU} / \mathrm{l})$ (Table 3). 
Table 1: Packed cell volume (PCV) and Haemoglobin level ( $\mathrm{Hb})$ in the control and treated groups on day 50 postpartum.

\begin{tabular}{lcc}
\hline Parameter/Gp & PCV $(\%)$ & Hb $(\mathbf{m g} / \mathbf{d l})$ \\
\hline Control & $39.6 \pm 1.8$ & $13.2 \pm 0.6$ \\
Pheny & $38.8 \pm 3.1$ & $13.0 \pm 1.1$ \\
Pheny+vit C & $40.4 \pm 2.1$ & $13.5 \pm 0.6$ \\
$C p$ & $39.0 \pm 1.9$ & $13.0 \pm 0.5$ \\
Pheny+cp & $40.0 \pm 2.4$ & $13.4 \pm 0.8$
\end{tabular}

Values are given as mean $\pm \mathrm{SD},(\mathrm{n}=5)$. Pheny=phenytoin; vit $\mathrm{C}=$ vitamin $\mathrm{C} ; C p=$ Calotropis procera extract. $\mathrm{P}>0.05$ in the treated groups versus the control group.

Table 2: Reduced glutathione (GSH) levels and lipid peroxidation (LPO) in the cerebellum of the control and treated groups on day 50 postpartum

\begin{tabular}{lll}
\hline Parameters/Gp & GSH & LPO \\
\hline Control & $2.0 \pm 0.7$ & $1.80 \pm 1.49$ \\
Pheny & $1.6 \pm 0.5$ & $4.00 \pm 2.19$ \\
Pheny+vit C & $1.8 \pm 0.4$ & $2.40 \pm 0.90$ \\
$C p$ & $2.0 \pm 0.0$ & $2.43 \pm 0.21$ \\
Pheny+ $C p$ & $1.8 \pm 0.8$ & $2.44 \pm 0.12$ \\
\hline
\end{tabular}

Values are given as mean $\pm \mathrm{SD},(\mathrm{n}=5)$. Reduced GSH is expressed in $\mu \mathrm{g} / \mathrm{g}$ tissue. Rate of $\mathrm{LPO}$ is expressed in $\mu \mathrm{mmol} / \mathrm{g}$ tissue. $\mathrm{Gp}=$ group; $\mathrm{Pheny}=$ phenytoin; vit $\mathrm{C}=$ vitamin $\mathrm{C} ; \mathrm{Cp}=$ Calotropis procera extract. $\mathrm{P}>0.05$ in the treated groups versus the control group.

Table 3: Alanin aminotransferase (ALT) and Aspartate aminotransferase (AST) levels in the control and treated groups on day 50 postpartum

\begin{tabular}{lcc}
\hline Parameters/Gp & Total activity of ALT & Total activity of AST \\
\hline Control & $65.2 \pm 7.1$ & $162.0 \pm 15.5$ \\
Pheny & $73.6 \pm 10.4$ & $203.4 \pm 34.5^{\mathrm{a}}$ \\
Pheny+vit C & $60.0 \pm 3.8^{\mathrm{d}}$ & $168.2 \pm 13.1$ \\
$C p$ & $68.8 \pm 2.4$ & $169.4 \pm 14.1$ \\
Pheny+cp & $67.2 \pm 6.2$ & $168.6 \pm 11.0$
\end{tabular}

Values are given as mean $\pm \mathrm{SD},(\mathrm{n}=5)$. Total activity of ALT is expressed in IU/l. activity of ALT is expressed in IU/l. $\mathrm{Gp}=$ group; Pheny=phenytoin; vit $\mathrm{C}=$ vitamin $\mathrm{C} ; C p=$ Calotropis procera extract. ${ }^{\mathrm{a}} \mathrm{P}<0.05$ versus control, ${ }^{\mathrm{d}} \mathrm{P}<0.05$ vs phenytoin group.

\section{DISCUSSION}

Phenytoin has been found to induce neurotoxicity by generating free radicals resulting in oxidative stress which leads to cellular damage and dysfunction (Liu et al., 1997). The human body has several mechanisms to counteract oxidative stress by producing antioxidants, which are either naturally produced in situ, or externally supplied through foods and / or supplements. These antioxidants act as "free radical scavengers" by preventing and repairing 
damages caused by ROS, and therefore can enhance the immune defenses and lower the risk of cancer and degenerative diseases (Valko et al., 2006).

The antiepileptic drug concentration profiled in breast milk follows the plasma concentration curve (Crawford, 2005). The total amount of drug transferred to infants via breast milk is usually much smaller than the amount transferred via the placenta during pregnancy. However, as drug elimination mechanisms are not fully developed in early infancy, repeated administration of antiepileptic drug via breast milk may lead to accumulation in the infant (Crawford, 2005). The results of the haematological parameters, $\mathrm{PCV}$ and $\mathrm{Hb}$ in this present study showed no statistically significant difference from the values of the control and other treated groups. These results could mean that anaemia was not induced and tend to confirm the works of Weber et al. (1977) that the haematological parameters (red cell foliate, red blood cell and haemoglobin count) did not show any alterations and no patient developed any sign of anaemia on long-term phenytoin treatment, several months and years after administration.

A number of observations suggest that detoxification of a xenobiotic free radical intermediate with antioxidants may provide embryoprotection (Wells et al., 1997). Glutathione, a low molecular weight endogenous antioxidant may be involved in the detoxification of a teratogenic reactive intermediate of phenytoin and/or in cytoprotection against oxidative stress. Glutathione plays a key role in maintaining the physiological balance between prooxidants and antioxidants. It has been reported to be first line of defense against oxidative stress (Xi and Chen, 2000). Glutathione depletors or inhibitors of glutathione synthesis potentiate phenytoin teratogenicity in mice (Wong and Wells, 1989).
In the present study, the decrease in the glutathione levels in the brain of phenytoin treated animals could be positively correlated to the increased rate of lipid peroxidation observed in the brain. Increased generation of ROS and LPO followed by apoptosis has been shown recently in cultures of cortical neurons from foetal brains with Down's syndrome (Busciglio and Yanker, 1995). The known moderate cerebellar hypoplasia in patients with Down's syndrome might reflect the effect of early degeneration of cerebellar progenitor cells by increased LPO and apoptosis in vivo (Olanow, 1993). Increased malondialdehyde, one of the end products of LPO can be interpreted as the result of cellular membrane damage initially caused by increased formation of radicals from LPO. Johnson et al. (1986) reported that increased intraneuronal calcium and lipid peroxidation might be mechanisms by which xenobiotics produce nerve injury.

Ferriero (2001) indicated that the increased susceptibility to oxidative injury can be explained by several mechanisms that facilitate the production of ROS from the increased presence of hydrogen peroxide that tends to accumulate because of immature defense mechanisms. It is indicated that the inadequate scavenging abilities inherent to developing systems are not sufficient to maintain glutathione store in neonatal neural tissue that also contains more available iron than is present in mature neural tissue. Glutathione depletion observed in the phenytoin-treated animals may be a contributory factor in the cascade of events leading to neurotoxicity in the developing cerebellum of the rats.

Vitamin $\mathrm{C}$ and extracts of $C$. procera extracts improved the glutathione levels and reduced the rate at which lipid peroxidation occurred in the brain. The increased LPO and reduced GSH registered a tendency to shift 
towards normalcy on co-administration of $C$. procera extracts. This confirms the position of C. procera as one important member of the flavonoid's family in ameliorating the effect of oxidative stress in biological tissues. The mechanism of the antioxidant activity demonstrated by $C$. procera and its fractions were not specifically studied in this research. However, Roy et al. (2005) reported that $C$. procera extracts increased hepatic levels of endogenous antioxidants such as superoxide dismutase, catalase and glutathione in alloxaninduced diabetes and that the antioxidant and antidiabetic properties of the extract was comparable to standard antidiabetic drug, glibenclamide. In this study, the methanolic extract of the leaves of $C$. procera was found to possess strong antioxidant activity which is comparable to the standard antioxidant supplement, vitamin C. The free radical scavenging property of $C$. procera may be one of the mechanisms by which the drug is effective as a traditional medicine.

About four to five percent of phenytoin is excreted unchanged in the urine and the half-life is 6-24 hours while the remainder is metabolized by hepatic microsomal enzymes (Rang and Dale, 1987). ALT and AST enzymes are excellent markers of hepatocellular injury reflecting, the hepatocellular integrity of the liver. Hepatocellular injury, and not necessarily cell death, is the trigger for the release of these enzymes into circulation (Katkov et al., 1991). The release of these cellular enzymes is one of the most sensitive parameters for the recognition of minute disturbances of cellular integrity. The elevation of these enzymes in the phenytoin treated animals showed a leakage of the enzymes from its intracellular compartment into the blood which may be due to relatively low oxygenation. These findings support the concept of phenytoin chronic intrauterine hypoxia/ischaemia and embryo- foetal toxicity (Wells et al., 1996). Vitamins C and extracts of $C$. procera decreased the ALT and AST levels probably by inhibit the generation of reacting oxygen species (ROS) and oxidative stress induced by phenytoin thereby preventing the release of free radical intermediates, which have been reported by Zablocka and Janusz (2008) to cause tissue necrosis and cellular damage.

In conclusion, a shift in the levels of reactive oxygen species towards pro-oxidants in developing rat brain can induce an oxidative stress on the cerebellum. To this end, the present study has shown that phenytoin administered to rats in pre and postnatal life induced oxidative stress in the cerebellum. The administration of vitamins $\mathrm{C}$ and methanolic leaf extracts of Calotropis procera appeared to reverse these changes when compared with the phenytoin-treated animals and as such tend to reduce the rate at which phenytoin induced toxicity in the developing rat cerebellum postnatally. Since the exposure to oxidants such as antiepileptic drugs (phenytoin) in the first trimester has been seen to be associated with an increased risk of major congenital anomalies (as most vital organs in the body develop within this period) in offspring, vitamins $\mathrm{C}$ and plants extract containing high amount of flavonoids, alkaloids and tannins supplementation in diets of pregnant epileptics receiving long term phenytoin therapy should be prescribed by physicians within this period and throughout pregnancy. Also, the antioxidants properties of these plants extract may prevent oxidative damage in neurodegenerative diseases and as such play a critical role in wellness and health maintenance. Characterization of the different fractions of $C$. procera should be further investigated to determine the maximum antioxidant activity. Also, as a result of the high medicinal and pharmacological values, availability and affordability of $C$. procera, 
and the results obtained from this study, further pharmacological and toxicological studies are required to establish the therapeutic uses of the plant and particularly with its active principles, so as to advise ethnomedical practitioners on the dosage and usage of the plant.

\section{REFERENCES}

Al-Robai AA, Abo-Khatwa AN, Danish EY. 1993a. Arab-Gulf Journal of Sci. Res., 11(3): 441-455.

Ames BN. 1983. Dietary carcinogens and anticarcinogens: oxygen radicals and degenerative diseases. Science, 221: 1256-1264.

Appleton R, Martland TPhillips B. 2002. Drug management for acute tonic-clonic convulsions including convulsive status epilepticus in children, Cochrane Database Syst. Rev. 4: CD001095.

Buck M. 1996. Phenytoin optimizing therapy in children, Pediatr. Pharmacother, 2(8): $1-7$.

Busciglio J, Yanker BA. 1995. Apoptosis and increased generation of reactive oxygen species in Down's syndrome neurons in vitro. Nature, 378: 776-779.

Chatterjee M, Saluja R, Kanneganti S. 2007. Biochemical and molecular evaluation of neutrophil NOS in spontaneous hypertensive rats. Cell Mol. Biol., 53: 8493.

Crawford P. 2005. Best practice guidelines for the management of women with epilepsy. Epilepsia, 46(9): 117-124.

Edman ED. 1983. Nutrient and Cardenolide composition of unextracted and solvent extracted procera. Calotropis J. Agr. Food Chem., 31(3): 509-513.

Ferriero MD. 2001. Oxidant mechanisms in neonatal hypoxia-ischaemia. Dev. Neurosci., 23: 198-202.
Gerber M, Boutron-Ruault MC, Hercberg S, Riboli E, Scalbert A, Siess MH. 2002. Food and cancer: state of the art about the protective effect of fruits and vegetables. Bulletin du Cancer, 89(3): 293 - 312.

Gey KF. 1990. The antioxidant hypothesis of cardiovascular disease: epidemiology and mechanisms. Biochem. Soc. Trans. 18: 1041- 1045.

Ghazanfar SA. 1989. Savana plants. In: An illustrated guide. Macmillian publishers Ltd: London; 115-118.

Guerrero AL, Pamiagua JA, Diaz Caseajo P, Cacho J, Martin J. 1997. Temporal cerebellar atrophy following phenytoin therapy. Neuroglia, 121(6): 259-261.

Huber H. 1985. Asclepiadaceae. In: A revised hand book of the Flora of Ceylon. Aemrind Publishing Co. Pvt. Ltd: New Delhi, 4: 73-79.

Hussein HI, Kamel AA, Abou-Zeid M, El Sabae AKH, Saleh MA. 1994. Uscharin the most potent molluscidal compound tested against land snails. Journal of Chemical Ecology, 20(1): 135-140.

Imamura T, Ejima A, Sahara M, Saito H, Tsuburaya K. 1992. Cerebellar atrophy and persistent cerebellar ataxia after acute intoxication of phenytoin. No To Shinkei. 44(2): 149-153.

Johnson JD, Meisenheimer TL, Isom GE. 1986. Cyanide induced neurotoxicity: Role of neuronal calcium. Toxicol. Appli. Pharmacol., 84(3): 464-469.

Katkov WN, Friedman LS, Cody H. 1991. Elevated serum alanine aminotransferase levels in blood donors: the contributions of hepatitis C virus. Ann. Intern. Med., 115: 882-884.

Kris-Etherton PM, Hecker KD, Bonanome A., Coval SM, Binkoski AE, Hilpert KF. 2002. Bioactive compounds in foods: their role in the prevention of cardiovascular diseases and cancer. 
American Journal of Medicine, 113(9B): $71 \mathrm{~S}-88 \mathrm{~S}$.

Liu CS, Wu HM, Kao SH, Wei YH. 1997. Phenytoin-mediated oxidative stress in serum of female epileptics: a possible pathogensis in the foetal hydantoin syndrome. Hum. Exp. Toxicol. 16(3): 177-181.

McNamara JO. 2001. Drugs effective in the therapy of epilepsies. In: The Pharmacological Basis of Therapeutics. Hardman JG, Limbird LE, Goodman A. Gilman (Eds.), Goodman and Gilman's, McGraw-Hill Co: New York; 521- 547.

Mossa JS, Tariq M, Mohsin A, Ageel AM, Al-Yahya MA, Al-said MS, Fatatullah S. 1991. Phurmucological studies of aerial parts of Calotropis procera. Am. J. Clin. Med., 19(3-4): 223-231.

NAPRALET 1984. List of Ethnomedical information on Calotropis procera. The Board of Trustees of the University of Illinois. USA.

Ney GC, Lantos G, Barr WB, Schaul N. 1994. Cerebellar atrophy in patients with longterm phenytoin exposure and epilepsy. Arch. Neurol., 51(8): 767-771.

Olanow CW. 1993. A radical hypothesis for neurodegeneration. Trends Neurosci., 16: 439-444.

Padhy BM, Srivastava A, Kumar VL. 2007. Calotropis procera latex afford protection against carbon tetrachloride-induced hepatotoxicity in rats. $J$. Ethnopharmacol., 113(3): 498-502.

Rang, H.P., Dale, M.M. 1987. Pharmacology. Longman Group; 535 - 537.

Roy S, Sehgal R, Padhy BM, Kumar VL. 2005. Antioxidant and protective effect of Latex of Calotropis procera against alloxan-induced diabetes in rats. $J$. Ethnopharmacol., 102(3): 470-473.

Salah N, Miller NJ, Paganga G, Tijburg L, Bolwell GP, Rice-Evans C. 1995.
Polyphenolic flavanols as scavengers of aqueous phase radicals and as chainbreaking antioxidants. Archives of Biochemistry and Biophysics, 322(2): 339 - 346.

Serafini M, Bellocco R, Wolk A, Ekstrom AM. 2002. Total antioxidant potential of fruit and vegetables and risk of gastric cancer. Gastroenterology, 123(4): 985 991.

Smith MA, Perry G, Richey PL, Sayre LM, Anderson V, Beal MF, Kowal N. 1996. Oxidative damage in Alzheimer's. Nature, 382: 120 - 121.

Sofowora A. 1984. Medicinal Plants and Traiditonal Medicine in Africa. John Willey and Sons Ltd: Ibadan; 142-146.

Srivastava GN. Chakravarti RN, Zaidi SH. 1962. Studies on anticoagulant therapy 3. In vitro screening of some Indian plant lattices for fibrinolytic and anticoagulant activity. Indian J. Med. Sci., 16: 873-877.

Tachibana T, Yoshiki T, Fukunishi K, Tanimura T. 1996. Estimated magnitude of behavioral effects of phenytoin in rats and its reproducibility: a collaborative behavioral teratology study in Japan, Physiol. Behav., 60(3): 941-952.

Tariq M, Al-Yahya MA, Al-Meshal EA, Mossa JS. 1984. Studies on Saudi plants causing neuromuscular blockade. Abtr. $9^{\text {th }} \quad$ International Congress of Pharmacology, London: Abstr. -2030p.

Temple NJ. 2000. Antioxidants and diseases: more questions than answers. Nutr. Res., 20(3): 449-459.

Valko M, Rhodes CJ, Moncola J, Izakovic M, Mazur M. 2006. Free radicals, metals and antioxidants in oxidative stress-induced cancer. Chem. Biol. Interact., 160: 1-40.

Vorhees CV. 1994. Developmental neurotoxicity induced by therapeutic and illicit drugs. Environ. Health Perspect, 102(2): 145- 153. 
Weber TH, Knuutila S, Tammisto P, Tontti K. 1977. Long-term of phenytoin: Effects on whole blood and red cell foliate and haematological parameters. Scand. $J$. Haematol., 18(2): 81-85.

Wells PG, Kim PM, Laposa RR, Nicol CJ, Parman T, Winn LM. 1997. Oxidative damage in chemical teratogenesis. Mutat Res., 396: 65-78.

Wells PG, Winn LM. 1996. Biochemical toxicology of chemical teratogenesis. Crit. Rev. Biochem. Mol. Biol., 31: 1-40.
Wong M, Wells PG. 1989. Modulation of embryonic glutathione reductase and phenytoin teratogenicity by 1, 3-bis (2chloroehtyl)-1-nitrosourea. J. Pharmacol Exp Ther., 250: 336-342.

Xi S, Chen LH. 2000. Effects of dietary fish oil on tissue glutathione and antioxidant defense enzymes in mice with murine AIDS. Nutr. Res., 20(9): 1287-1299.

Zablocka A, Janusz M. 2008. The two faces of reacting oxygen species. Postepy. Hig. Med. Dosw., 62: 118 - 124. 